ORIGINAL ARTICLE

\title{
Cow allergen (Bos d2) and endotoxin concentrations are higher in the settled dust of homes proximate to industrial-scale dairy operations
}

\author{
D’ Ann L. Williams ${ }^{1}$, Meredith C. McCormack ${ }^{2}$, Elizabeth C. Matsui ${ }^{2}$, Gregory B. Diette ${ }^{1,2}$, Shawn E. McKenzie ${ }^{1}$, Alison S. Geyh ${ }^{1}$ and \\ Patrick N. Breysse ${ }^{1}$
}

Airborne contaminants produced by industrial agricultural facilities contain chemical and biological compounds that can impact the health of residents living in close proximity. Settled dust can be a reservoir for these contaminants and can influence long-term exposures. In this study, we sampled the indoor- and outdoor-settled dust from 40 homes that varied in proximity to industrialscale dairies (ISD; industrial-scale dairy, a term used in this paper to describe a large dairy farm and adjacent waste sprayfields, concentrated animal feeding operation or animal feeding operation, that uses industrial processes) in the Yakima Valley, Washington. We analyzed settled dust samples for cow allergen (Bos d2, a cow allergen associated with dander, hair, sweat and urine, it is a member of the lipocalin family of allergens associated with mammals), mouse allergen (Mus m1; major mouse allergen, a mouse urinary allergen, in the lipocalin family), dust mite allergens (Der p1 (Dermatophagoides pteronissinus 1) and Der f1 (Dermatophagoides farinae 1)), and endotoxin (a component of the cell walls of gram negative bacteria, lipopolysaccharide, which can be found in air and dust and can produce a strong inflammatory response). A concentration gradient was observed for Bos d2 and endotoxin measured in outdoor-settled dust samples based on proximity to ISD. Indoor-settled dust concentrations of Bos d2 and endotoxin were also highest in proximal homes. While the associated health effects of exposure to cow allergen in settled dust is unknown, endotoxin at concentrations observed in these proximal homes $(100 \mathrm{EU} / \mathrm{mg})$ has been associated with increased negative respiratory health effects. These findings document that biological contaminants emitted from ISDs are elevated in indoor- and outdoor-settled dust samples at homes close to these facilities and extend to as much as three miles (4.8 km) away.

Journal of Exposure Science and Environmental Epidemiology (2016) 26, 42-47; doi:10.1038/jes.2014.57; published online 20 August 2014

Keywords: environmental monitoring; inhalation exposure; particulate matter; pulmonary disease

\section{INTRODUCTION}

In the last 50 years, the industrialization of agriculture has changed rural environments. Regulatory agencies attempting to meet federal and state air and water quality standards are progressively more concerned about emissions from industrialscale farming facilities. ${ }^{1,2}$ A number of hazardous airborne contaminants are produced by industrial-scale animal facilities (IAF, a term used to describe industrial farms and facilities with animals used for food production, cow, swine, and fowl) and there is a valid concern that communities located close to these facilities are at increased risk for negative health outcomes associated with exposure to particulate matter (PM) containing animal waste products and other pollutants released from IAF. ${ }^{3-8}$

To investigate the impact of industrial-scale dairies (ISD), facility and adjacent sprayfields, on community exposures, we conducted an assessment of settled dust content in and around residences of the Yakima Valley, an arid region in Washington State experiencing the growth of ISDs. We chose settled dust components thought to be carried through the air as PM that could be tied to the presence of dairy operations including cow allergen (Bos d2) and endotoxin. Endotoxins are ubiquitous biologically active components of bacteria and dust, and do not need to be transported by a viable organism to be a health concern. We also chose to analyze settled dust samples for mouse allergen and dust mite allergens as negative controls, since these allergens are not associated a priori with dust transport from dairy facilities. In a previous paper, we reported that airborne PM concentrations were 1.3 times higher inside homes close to the dairy facilities compared with homes that were farther away. ${ }^{9}$ Bos $\mathrm{d} 2$, a cow allergen and component of airborne particles, was 10 times higher showing a distinct difference in the composition of airborne particulate matter based on proximity to ISD. ${ }^{9}$ Measured components of settled dust such as allergens and endotoxin, a powerful inflammatory agent that can act synergistically with other agents to cause respiratory health effects, ${ }^{6,10}$ can serve as important indicators for evaluating integrated exposure over time to contaminants that may be associated with home, local, or regional health hazards. ${ }^{11}$

To add to our previous work which investigated potentially shorter-term airborne exposure to contaminants, in this paper we report on the distribution of dairy-related animal waste contaminants found in settled dust inside and outside homes as a function of distance to the dairy facilities.

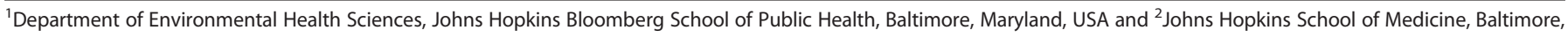

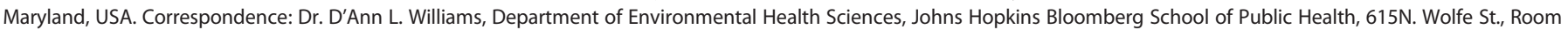
E6618, Baltimore, MD 21205 USA.

Tel.: 410-614-5755. Fax: 410-955-9334.

E-mail: dwilli20@jhu.edu

Received 4 September 2013; accepted 12 May 2014; published online 20 August 2014 


\section{MATERIALS AND METHODS}

Sample Population and Settled Dust Collection

A total of 40 homes in the Yakima Valley, representing a range of distances to commercial dairy facilities, were recruited for participation in this study. Methods used to identify potential homes for recruitment are discussed in detail elsewhere. ${ }^{9}$ Homes that had a dairy worker or cows on the property and those that had smoking of any kind were excluded. In addition, the participant must have resided in the home for at least six months to be included. Settled dust samples from each house were collected and analyzed for cow allergen (Bos d2), endotoxin, mouse allergen (Mus m1), and dust mite allergen (Der p1 and Der f1). Cow allergen was chosen as a dairy-specific surrogate for determining the influence of contaminants from dairies. Endotoxin, also associated with animal waste products, is a less specific indicator, however, since there are other potential non-dairy sources (e.g., humans, grains, pets, and other animals) of dust contamination. We also chose three common indoor allergens, mouse and dust mite, not expected to be associated with proximity to dairies to serve as negative controls.

Indoor and outdoor vacuum dust samples were collected using an Oreck BB1100DB, portable vacuum cleaner (Oreck, Cookeville, TN, USA) equipped with MITEST adaptors following Indoor Biotechnologies dust collection, and processing protocols (Indoor Biotechnologies, Charlottesville VA, USA). Samples were stored in a $0^{\circ} \mathrm{F}$ freezer in Yakima and shipped overnight to $\mathrm{JHSPH}$ at $4{ }^{\circ} \mathrm{C}$ and then stored in a $-20^{\circ} \mathrm{C}$ freezer at JHSPH until blinded analysis. Dust was pre-processed using a number 50,350 $\mu \mathrm{m}$ diameter sieve, VWR No. 57332146 (VWR, Bridgeport, CT, USA). Dust sieves were cleaned using pyrogen-free techniques and dust was stored in pyrogenfree glass vials. Dust was then aliquoted and a portion of the sample was analyzed for Bos d2, Mus m1, Der p1 and Der f1 allergens, and endotoxin.

Settled dust samples were collected in homes following established protocols. ${ }^{12}$ Indoor-settled dust samples were collected from three surfaces: (1) from a bed and carpeting around the bed in a bedroom; (2) from an upholstered piece of furniture; and (3) from a hard surface which was off of the floor, such as an elevated shelving unit or window sill. Seven participants did not allow vacuuming in the bedroom, so an extra upholstered surface in the primary living area was vacuumed instead.

Samples from each surface were analyzed separately in three categories: bedroom, soft furniture, and hard surface when sufficient dust was available. In five homes, there was an insufficient amount of dust collected for analysis of these individual categories, so the samples from the three areas were pooled and only one indoor-settled dust value was obtained for those homes. To allow statistical comparison of all home groups, results for the three indoor samples for each home were averaged and one mean value was reported per home for all analytes. To confirm the rationale for pooling dust samples, we compared analyte results by site of sample (bedroom, soft furniture, and so on) when all three were available and found no statistical difference between sample sites using Kruskal-Wallis analysis.

Outdoor settled dust samples were collected using the same methods as indoor samples. Samples were collected in a location off of the ground in the outdoor environment that would be subjected to airborne dust accumulation. Outdoor carpets or doormats were not sampled as the dust would not entirely be representative of settled dust, since dust on these surfaces can include particles carried on shoes and other physical items. Shelving, tables, chairs/outdoor furniture were preferentially chosen when available. If these options were not available, window sills, door frames, and house siding were sampled. When more than one outdoor-settled dust sample was analyzed for individual homes, these values were averaged and one mean value was reported by home.

\section{Housing Characteristics}

Housing characteristics including house age, number of people living in the home, self-reported or observed evidence of a pet typically cats or dogs, presence of livestock other than resident cows or cattle, and presence of air conditioning were noted for each home using standardized questionnaires. ${ }^{13}$

\section{Sample Analysis}

Bos d2 concentrations were determined from the sieved settled dust samples by Indoor Biotechnologies Charlottesville, VA, USA using an enzyme-linked immunosorbent assay. ${ }^{14}$ Sieved settled dust was analyzed for Mus $\mathrm{m} 1$ and Der f1, Der $\mathrm{p} 1$ in the Matsui Laboratory, Johns Hopkins School of Medicine. Mus m1, Der p1, and Der f1 were analyzed by enzymelinked immunosorbent assay. ${ }^{15,16}$ The analytical detection limits for the analysis of the allergens Bos d2, Mus m1, Der p1, and Der f1 were $0.03 \mu \mathrm{g} / \mathrm{g}$, $3.9 \mathrm{ng} / \mathrm{g}, 39 \mathrm{ng} / \mathrm{g}$, and $9.8 \mathrm{ng} / \mathrm{g}$, respectively.

Endotoxin was measured in sieved settled dust samples using Limulus amebocyte lysate (Limulus amebocyte lysate analysis used to measure endotoxin, made from the blood of a horseshoe crab) analysis as a single batch by the Thorne Laboratory, University of lowa. The detection limit of airborne endotoxin concentrations was $0.024 \mathrm{EU} / \mathrm{ml}^{17}$

\section{Statistical Analysis}

Exploratory data analysis was conducted using Microsoft Excel (Redmond, WA, USA) and Stata SE 11.0 (College Station, TX, USA). Data were examined and descriptive statistics were generated to determine measures of central tendency and data distributions. Student's $t$-tests were used to compare results among proximal, intermediate and distal homes. As the data were not normally distributed, analytes were compared by group using the nonparametric Kruskal-Wallis test and the Mann-Whitney U-test. Samples that were below the limit of detection of the analytical method were assigned a value of one-half the limit of detection and retained for statistical analysis. $^{18}$

\section{RESULTS}

Homes Evaluated and Housing Characteristics

A total of 83 homes were contacted and 40 homes agreed to allow environmental sampling. Homes were stratified into three groups to evaluate proximity and different exposure profiles, 20 proximal homes $(0.25$ mile, $0.4 \mathrm{~km})$ or less to an ISD, seven intermediate homes (greater than 2.5-3 miles, 4-4.8 km) from and ISD and 13 distal homes (greater than 3 miles, greater than $4.8 \mathrm{~km}$ ) from an ISD. Participant identification, recruitment and housing characteristics, and rationale for distance stratification are summarized in our previous publication. ${ }^{9}$ In general, characteristics of study homes by age of home, number of people living in home, air conditioning use, and pet presence were not significantly different by home group.

\section{Settled Dust Sample Results and Study Home Comparisons}

Table 1 provides a summary of the overall sampling (indoor and outdoor) results. Bos d2 was detected in $50 \%$ of the settled dust samples. Endotoxin was detected in $100 \%$ of settled dust samples. Mus $\mathrm{m} 1$ was detected in most homes $(77 \%)$, while dust mite

Table 1. Summary statistics of settled dust samples.

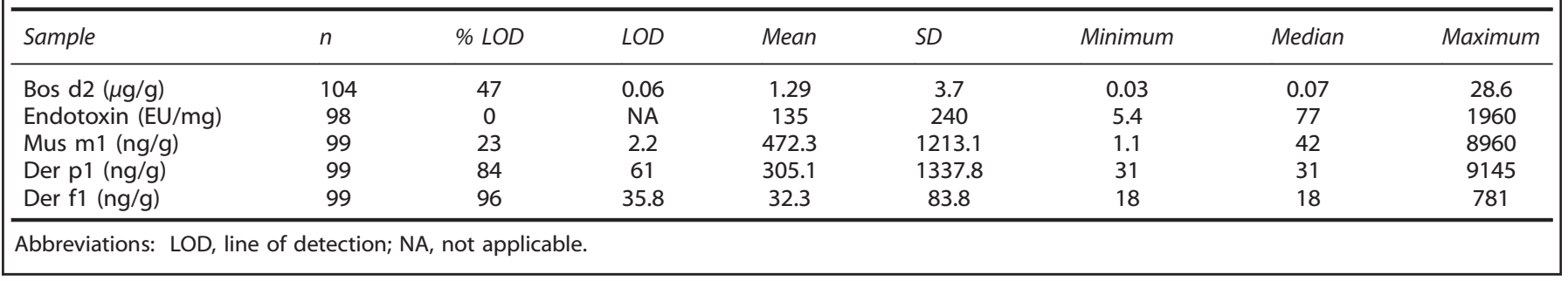


Table 2. Summary of outdoor-settled dust samples_proximal (P), intermediate (I) and distal (D)homes.

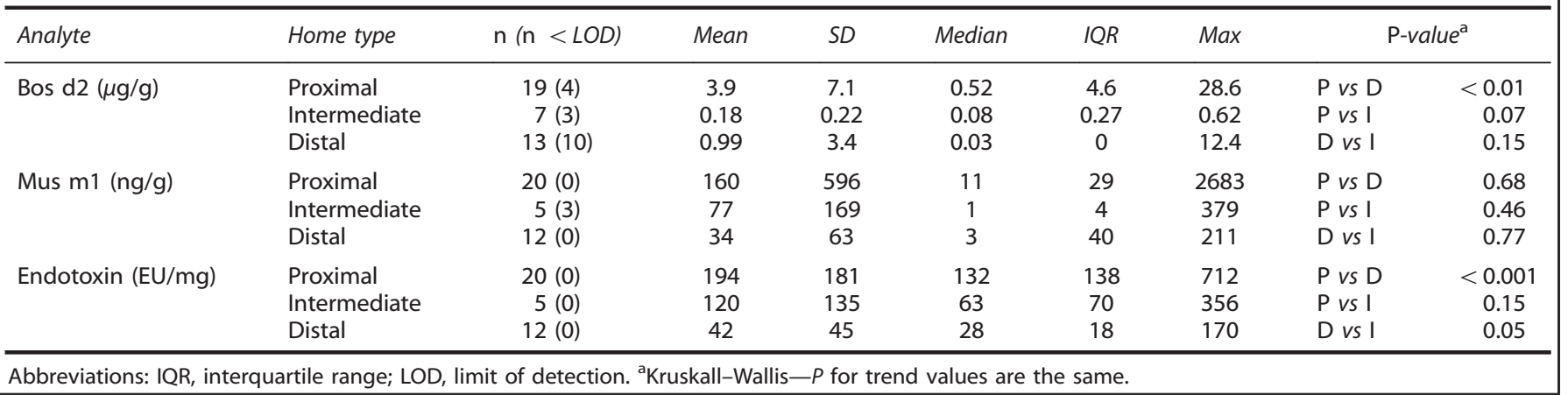

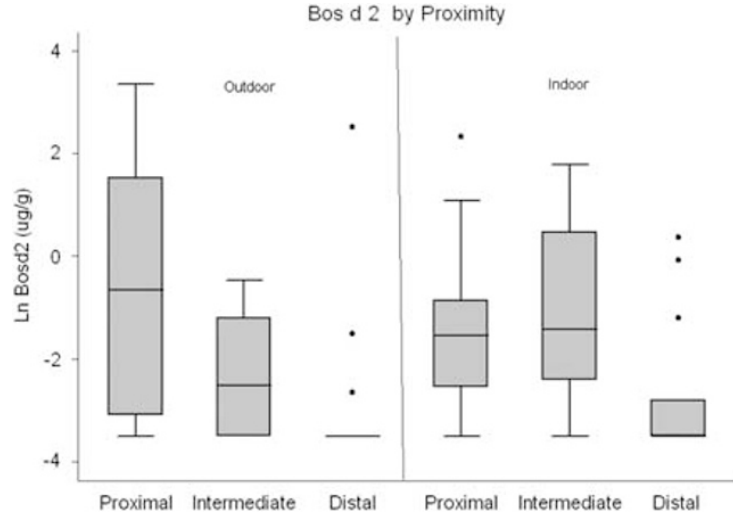

Figure 1. Box plot comparing outdoor and indoor log concentrations of Bos $\mathrm{d} 2$ in settled dust between proximal, intermediate, and distal homes.

allergen was rarely detected in settled dust samples (3 and 15\% for Der p1 and Der f1, respectively).

Outdoor settled dust. Outdoor settled dust concentrations of cow allergen, mouse allergen, and endotoxin are summarized in Table 2, and illustrated in Figures 1 and 2. Cow allergen in outdoor dust followed a concentration gradient from proximal to distal homes. Cow allergen was detected in $79 \%, 57 \%$, and $23 \%$ of proximal, intermediate, and distal homes, respectively. Median cow allergen concentrations in proximal homes were 17 times higher $(P<0.01)$ than distal homes. Differences in cow allergen between proximal and intermediate homes trended toward significance $(P=0.07)$, while intermediate homes were 2.7 times higher $(P=0.15)$ than distal homes.

Endotoxin was detected in $100 \%$ of outdoor samples. Similar to cow allergen, endotoxin concentrations exhibited a distinct gradient with distance. Median endotoxin concentrations in the outdoor dust of proximal homes was five times higher $(P<0.01)$ than distal homes and intermediate homes were two times higher $(P=0.05)$ than distal homes.

Median outdoor dust concentrations of mouse allergen were not significantly different between proximal and distal homes. Mouse allergen concentrations were lowest in the intermediate homes with only two out of five samples above the limit of detection. Dust mite allergens were not found in any of the outdoor-settled dust samples from distal or intermediate homes and in proximal samples only two of 20 were above the limit of detection.

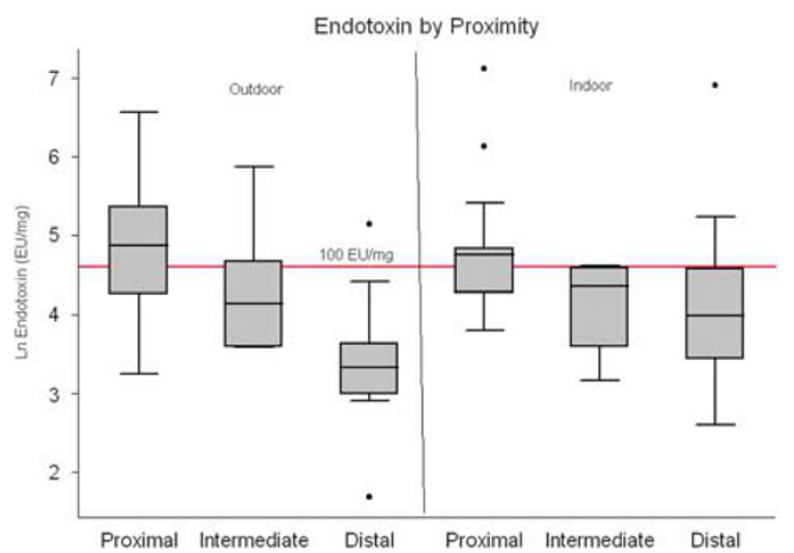

Figure 2. Box plot comparing outdoor and indoor log concentrations of endotoxin in settled dust between proximal, intermediate, and distal homes. Reference line indicates associated health effects level of $100 \mathrm{EU} / \mathrm{mg}$.

Indoor-settled dust. Indoor-settled dust sampling results for proximal, intermediate, and distal homes are summarized in Table 3, and illustrated in Figures 1 and 2. Similar to outdoor dust results, indoor cow allergen was observed with $80 \%, 86 \%$, and $46 \%$ of dust samples having detectable cow allergen in proximal, intermediate, and distal homes, respectively. As with the outdoorsettled dust and proximity, the indoor Bos $\mathrm{d} 2$ concentrations in the settled dust of proximal and intermediate homes were statistically similar as illustrated in Figure 1. Indoor concentrations of Bos $\mathrm{d} 2$ in both proximal and intermediate homes were higher than distal homes (six and eight times higher, respectively).

Median indoor endotoxin dust concentrations were two times greater in proximal homes compared with intermediate $(P=0.03)$ and three times greater than distal homes $(P=0.02)$. While endotoxin concentrations in distal homes were 1.3 times higher than the intermediate homes, this difference was not statistically significant. Indoor concentrations of endotoxin in settled dust significantly vary with distance to facility as illustrated in Figure 2.

No concentration gradient with distance was observed for indoor mouse allergen. Mouse allergen median concentrations in indoor-settled dust were not significantly different between proximal $(1105 \mathrm{ng} / \mathrm{g})$ and distal homes $(1303 \mathrm{ng} / \mathrm{g})$. However, Mus $\mathrm{m} 1$ was five times higher in the indoor dust of proximal homes compared with intermediate homes, median $1105 \mathrm{ng} / \mathrm{g}$ and $240 \mathrm{ng} / \mathrm{g}$, respectively $(P=0.02)$, as shown in Table 3 . For all homes, over $57 \%$ of indoor-settled dust mite, Der p1 and Der f1, concentrations were below the limit of detection and further statistical analysis was not conducted. 
Table 3. Summary of indoor-settled dust samples-proximal (P), intermediate (I) and distal (D) homes.

\begin{tabular}{|c|c|c|c|c|c|c|c|c|c|}
\hline Analyte & Home type & $\mathrm{n}(\mathrm{n}<L O D)$ & Mean & $S D$ & Median & $I Q R$ & Max & \multicolumn{2}{|c|}{ P-value ${ }^{a}$} \\
\hline Bos d2 ( $\mu \mathrm{g} / \mathrm{g})$ & Intermediate & $7(1)$ & 1.25 & 2.16 & 0.24 & 1.52 & 6.0 & P vs I & 0.56 \\
\hline \multirow[t]{3}{*}{ Mus m1 (ng/g) } & Proximal & $20(0)$ & 1122 & 1536 & 450 & 1567 & 5529 & P vs D & 0.22 \\
\hline & Intermediate & $7(0)$ & 233 & 454 & 46 & 93 & 1266 & P vs I & 0.02 \\
\hline & Distal & $13(0)$ & 1302 & 3226 & 252 & 650 & 11908 & D vs I & 0.19 \\
\hline Endotoxin (EU/mg) & Distal & $13(0)$ & 133 & 264 & 54 & 67 & 998 & D vs I & 0.60 \\
\hline
\end{tabular}

\section{DISCUSSION}

Results of this study indicate that pollutants associated with waste products from ISD facilities are present at higher concentrations in the indoor- and outdoor-settled dust of proximal homes (within 0.25 miles, $0.4 \mathrm{~km}$ ) compared with distal homes (greater than 3 miles, $4.8 \mathrm{~km}$ ). Potential sources of cow allergen and endotoxin in the Lower Yakima Valley include a large number of ISD facilities and a single cattle feedlot. There are no other large-scale animal operations of other species in the valley. As expected, mouse allergen, a contaminant not specifically related to dairy facilities, showed no clear concentration gradient by home proximity to ISD.

\section{Bos $\mathrm{d} 2$}

The detection of cow allergen is significant and was chosen as a dairy-specific surrogate to determine the spatial extent of contamination from dairies. Since homes with dairy workers or homes with resident cows were excluded from this study, the presence of cow allergen in both outdoor and indoor dust suggests that the contamination was likely due to the resuspension of waste materials from the dairy operations (or the single feedlot) or from the application of these ISD wastes to surrounding fields. Its detection suggests that cow allergen may be an important health risk for allergic sensitization and disease, as well as an asthma trigger for sensitized individuals. ${ }^{4,19-21}$ In our study, cow allergen was detected in $31 \%$ of the distal homes that were more than 3 miles from an ISD. In addition, the detection of cow allergen serves as a surrogate for other potentially harmful exposures that may also be present in affected communities due to the dispersal of waste contaminants from the facilities.

The health consequences of the accumulation of dairy associated waste products in the homes in the Lower Yakima Valley are uncertain but warrant future investigation. Health studies of IAF workers report that workers suffer from a range of adverse health effects including but not limited to, cardiovascular and respiratory diseases, skin disorders, cancer and non-cancer diseases related to pesticides. ${ }^{22-25}$ Occupational studies which investigated Bos $\mathrm{d} 2$ found exposures can induce respiratory inflammation, rhinitis, and dermatitis among sensitized dairy workers. ${ }^{20,26,27}$ Elevated concentrations of cow allergen have been found inside barns, sheds, stables, and the living quarters of current dairy farm workers and in homes of former dairy workers. ${ }^{19,28}$

In our study, six indoor dust samples had concentrations of Bos $\mathrm{d} 2$ in settled dust above $1 \mu \mathrm{g} / \mathrm{g}$. Three of the 20 proximal homes in this study had Bos d2 concentrations above $10 \mu \mathrm{g} / \mathrm{g}$, with one sample found to contain $28 \mu \mathrm{g} / \mathrm{g}$ Bos d2. These concentrations fall into a range relevant to health as discussed below. It is important to note that the analysis of Bos $d 2$ is not commonly conducted and that results obtained using different analytical methods to detect allergens should be compared with caution. ${ }^{29}$ Hinze et al. ${ }^{19}$ measured settled dust concentrations of Bos $d 2$ in the homes of
German dairy workers which were not attached to barns, ranging from 40 to $82 \mu \mathrm{g} / \mathrm{g}$. Living quarters that were located in the same building as the cows had settled dust Bos d2 concentrations ranging from 103 to $150 \mu \mathrm{g} / \mathrm{g}$. For workers who were sensitized to cow allergen, lgE responses occurred at Bos d2 concentrations ranging from 1 to $20 \mu \mathrm{g} / \mathrm{g}$ in dust collected from floors in their homes which were part of a dairy farm. ${ }^{30}$ These findings suggest that even relatively low concentrations can elicit systemic responses in sensitized individuals. Our findings for homes in close proximity to, but not located on an ISD are in the lower end of ranges reported for occupational exposures.

Our study results indicate that outdoor cow allergen demonstrated a clear pattern of decrease from proximal to intermediate to distal. However, while indoor concentrations of Bos d2 in settled dust were significantly greater in proximal compared with distal homes, proximal and intermediate homes were statistically indistinguishable. The penetration of pollutants from outdoors to indoors is governed by many complex factors that can be influenced by the air-exchange rates from outdoors to indoors that were not assessed as a part of this study. These include type of heating and air conditioning, the opening and closing of doors and windows, the housing style and construction, the amount of insulation, among other factors. These factors may explain why the pattern of decrease in indoor cow allergen was not the same as observed for outdoor samples.

While we don't have direct evidence that the cow allergen came from dairy facilities, the spatial association with distance provides strong indirect evidence that the dairies are the source of the pollution and suggest that dairy facilities could impact in-home dust concentrations at a distance of up to 3 miles $(4.8 \mathrm{~km})$ from ISD. It is possible that cross-reactivity with other allergens may be interfering with the cow allergen assay contributing some of the variability. ${ }^{31}$ The paucity of data on cow allergen concentration in typical houses precludes comparison with household cow allergen exposure in the general population.

\section{Endotoxin}

As a component of animal manure, endotoxin is generally found in greater amounts in agricultural environments but can vary greatly depending on the environment and agricultural processes used. ${ }^{17,32-36}$ Mueller-Anneling et al. ${ }^{37}$ conducted an evaluation of endotoxin in air samples of various agricultural environments in California. In the California study, the highest airborne concentrations of endotoxin were found in the ambient air of a community in close proximity to industrial dairy production and were associated primarily with $\mathrm{PM}_{10}$. In lowa, the same group measured airborne endotoxin at sites in close proximity to a swine facility and also found elevated concentrations close to facilities. ${ }^{37,38}$ While we did not measure airborne endotoxin as a part of our study, settled dust is considered a reservoir for airborne materials through surface deposition. Our settled dust results are therefore 
consistent with the above-mentioned studies that found higher airborne endotoxin close to swine and dairy facilities.

Waser et al. ${ }^{39}$ studied settled dust in farm and non-farm homes in Germany, Austria, and Switzerland and concentrations of endotoxin in farming homes were up to two times higher than those of non-farming homes depending on country and sample location. ${ }^{39}$ Schram et al. $^{40}$ also found that endotoxin concentrations in settled dust were 1.2-3.6 times greater in farm environments as compared with other non-faming environments. Endotoxin concentrations measured in our study in the United States extend the findings of these European studies with indoor proximal (rural) environments being approximately two times higher than distal environments and outdoor proximal environments being approximately 4.5 times higher than distal (urban) environments.

Thorne et al. $^{21}$ report that the influence of IAF on airborne endotoxin levels diminish to background at about $500 \mathrm{ft}(0.15 \mathrm{~km})$ from the facility to the "no effect level" of $50 \mu \mathrm{g} / \mathrm{m}^{3}$. The relationship observed in this study between endotoxin levels in settled dust and distance to facility suggests that airborne PM from these facilities can influence endotoxin levels in airborne and settled dust across a much wider geographical area, greater than 3 miles $(4.8 \mathrm{~km})$ or $15840 \mathrm{ft}$.

Thorne et al. $^{41}$ also found that endotoxin concentrations in settled dust were highly correlated with increased asthma diagnosis, asthma symptoms, asthma medication use, and wheeze in the National Survey of Lead and Allergens in Housing study. Concentrations on the order of $100 \mathrm{EU} / \mathrm{mg}$, found in urban homesettled dust were associated with infant wheeze during the first year of life. ${ }^{42}$ Over $55 \%$ of the proximal homes in this study had indoor concentrations of endotoxin that were over this threshold of $100 \mathrm{EU} / \mathrm{mg}$; in contrast, these health-relevant concentrations were observed in only $23 \%$ of distal homes.

Outdoor concentrations of endotoxin followed the same trend. Thirteen of 20 proximal homes vs only one distal home had outdoor endotoxin concentrations greater than $100 \mathrm{EU} / \mathrm{mg}$. We found dust concentrations of endotoxin that are relevant to respiratory health effects in both the indoor and outdoor environments of proximal homes. These health-relevant concentrations will likely affect exposed populations which include children, atopic individuals, the elderly, and other susceptible populations at distances far greater than just those immediately adjacent to dairy facilities. ${ }^{41,42}$

Like Bos $\mathrm{d} 2$, endotoxin was also spatially associated with proximity to dairy facilities. While endotoxin has other sources and is therefore not exclusively the result of living close to dairies, the overlapping patterns of increasing dust concentration with proximity to dairies for both cow allergen and endotoxin strongly suggest that living close to ISD results in an increase in exposure to waste products which accumulate in dust both inside and outside of the home and may be relevant to health outcomes. These contaminants can include microorganisms associated with animal wastes including Escherichia coli and other bacteria; chemicals, growth hormones and antibiotics used in dairy operations and excreted by the animals. ${ }^{43-45}$

\section{Limitations}

As in most observational studies, there are associated limitations. This cross-sectional study gives us only a snapshot of the exposure profile and the applicability of these results must be interpreted with some caution. A more comprehensive assessment should include measurements over longer periods of time and across multiple seasons.

Comparisons using the intermediate homes are limited by sample size $(n=7)$. Another limitation is that information on home cleanliness, recreational exposure to cattle, and use of cow manure as a home fertilizer was not collected. Other information that was not collected was wind direction and orientation to facility. The absence of current and accurate information on the specific farming processes used, number of facilities, number of cows, actual facility size including sprayfields and other factors that may play a significant role for exposure could account for the observed variability in both Bos $\mathrm{d} 2$ and endotoxin concentrations in this study.

We did not take wind direction into account in our interpretation of the impact of proximity. The absence of wind information is not a significant limitation, since the dust samples were collected from locations thought to represent long-term (months) accumulation. While the prevailing wind direction is west to east, the wind direction at any location is highly variable from day to day depending on the time of year and local weather events.

\section{CONCLUSION}

This study provides additional evidence that contaminants associated with waste products from ISD facilities are found in settled dust inside and outside homes up to a distance of greater than 3 iles $(4.8 \mathrm{~km})$ away. More than half of the homes within 0.25 mile $(0.4 \mathrm{~km})$ of a dairy facility had elevated endotoxin concentrations in settled dust which were observed at concentrations relevant to adverse health outcomes. In addition, Bos d2 concentrations observed in this study may be a source of exposure to sensitized individuals, leading to health effects, as allergen exposure has been found to be a risk factor for asthma exacerbation. These findings reinforce community concerns about exposure to wasterelated pollutants associated with ISD and substantiate the need for larger, well-designed health studies of communities influenced by ISD facilities.

\section{CONFLICT OF INTEREST}

The authors declare no conflict of interest.

\section{ACKNOWLEDGEMENTS}

This research was supported by The Johns Hopkins Center for a Livable Future, The National Institute of Environmental Health Sciences (PO1ES09606), U.S. Environmental Protection Agency (POR-826724) and The Johns Hopkins NIEHS Center in Urban Environmental Health (P30ES03819).

\section{REFERENCES}

1 Centner TJ. Regulating concentrated animal feeding operations to enhance the environment. Environ Sci Policy 2003; 6: 433-440.

2 Centner TJ. Enforcing environmental regulations: concentrated animal feeding operations. MO Law Rev 2004; 69: 697.

3 Thu KM. Public health concerns for neighbors of large-scale swine production operations. J Agr Saf Health 2002; 8: 175-184.

4 Mirabelli M, Wing S, Marshall S, Wilcosky T. Asthma symptoms among adolescents who attend public schools that are located near confined swine feeding operations. Pediatrics 2006; 118: 66-75.

5 Radon K, Schulze A, Ehrenstein V, van Strien RT, Praml G, Nowak D et al. Environmental exposure to confined animal feeding operations and respiratory health of neighboring residents. Epidemiology 2007; 18: 300-308.

6 Thorne P. Environmental health impacts of concentrated animal feeding operations: anticipating hazards-searching for solutions. Environ Health Persp 2007; 115: 296-297.

7 Wing S, Horton R, Marshall S, Thu K, Tajik M, Schinasi L et al. Air pollution and odor in communities near industrial swine operations. Environ Health Persp 2008; 116: 1362-1368.

8 Centner TJ. Nuisances from animal feeding operations: reconciling agricultural production and neighboring property rights. Drake J Agr Law 2006; 11: 5.

9 Williams DL, Breysse PN, McCormack MC, Diette GB, McKenzie S, Geyh AS et al. Airborne cow allergen, ammonia and particulate matter at homes vary with distance to industrial scale dairy operations: an exposure assessment. Environ Health 2011; 72: 10-1186. 
10 Park JH, Spiegelman DL, Burge HA, Gold DR, Chew GL, Milton DK et al. Longitudinal study of dust and airborne endotoxin in the home. Environ Health Persp 2000; 108: 1023-1028.

11 Butte W, Heinzow B. Pollutants in house dust as indicators of indoor contamination. Rev Environ Contam T 2002; 175: 150-156.

12 Eggleston PA. Home environmental intervention in inner-city asthma: a randomized control trial. Ann Allerg Asthma Im 2005; 95: 518-524.

13 Hansel NN, Breysse PN, McCormack MC, Matsui EC, Curtin-Brosnan J, Williams DL et al. A longitudinal study of indoor nitrogen dioxide levels and respiratory symptoms in inner-city children with asthma. Environ Health Persp 2008; 116: 1428-1433.

14 Virtanen T, Zeiler T, Rautiainen J, Taivainen A, Pentikainen J, Rytkonen $\mathrm{M}$ et al. Immune reactivity of cow-asthmatic dairy farmers to the major allergen of cow (BDA20) and to other cow-derived proteins. The use of purified BDA20 increases the performance of diagnostic tests in respiratory cow allergy. Clin Exp Allerg 1996; 26: 188-196.

15 Chapman MD, Heymann PW, Wilkins SR, Brown MJ, Platts-Mills TA. Monoclonal immunoassay for major dust mite (Dermatophageides) allergens, Der $\mathrm{p} \mathrm{I}$ and Der $\mathrm{fl}$, and quantitative analysis of the allergen content of mite and house dust extracts. J Allergy Clin Immun 1987; 80: 184-194.

16 Korpi A, Mäntyjärvi R, Rautiainen J, Kaliste E, Kalliokoski $\mathrm{P}$, Renström A et al. Detection of mouse and rat urinary aeroallergens with an improved ELISA. J Allergy Clin Immun 2004; 113: 677-682.

17 Thorne PS. Inhalation toxicology models of endotoxin- and bioaerosol-induced inflammation. Toxicology 2000; 152: 13-23.

18 Helsel D. Nondetects and Data Analysis: Statistics for Censored Environmental Data. Wiley-Interscience: Hoboken, NJ, USA, 2005.

19 Hinze S, Bergmann K, Lowenstein H, Hansen G. Cow hair allergen (Bos d2) content in house dust: correlation with sensitization in farmers with cow hair asthma. Int Arch Allergy Imm 1997; 112: 231-237.

20 Zeiler T, Taivainen A, Mantyjarvi R, Tukiainen $\mathrm{H}$, Rautiainen J, Rytkonen-Nissinen M et al. Threshold levels of purified natural Bos $\mathrm{d} 2$ for inducing bronchial airway response in asthmatic patients. Clin Exp Allergy 2002; 32: 1454-1460.

21 Thorne PS, Ansley AC, Perry SS. Concentrations of bioaerosols, odors, and hydrogen sulfide inside and downwind from two types of swine livestock operations. J Occup Environ Hyg 2009; 6: 211-220.

22 Schenker MB, Christiani D, Cormier Y, Dimich-Ward H, Doekes G, Dosman J et al. Respiratory health hazards in agriculture. Am J Resp Crit Care 1998; 158: S1-S76.

23 Cole D, Todd L, Wing S. Concentrated swine feeding operations and public health: a review of occupational and community health effects. Environ Health Persp 2000; 8: 685-699.

24 Kirkhorn S, Schenker MB. Human health effects of agriculture: physical diseases and illnesses. Agricultural Safety and Health Conference: Using Past and Present to Map Future Actions 2001.

25 Liebers V, Bruning T, Raulf-Heimsoth M. Occupational endotoxin-exposure and possible health effects on humans. Am J Ind Med 2006; 49: 474-491.

26 Spiewak R, Dutkiewicz J, Skorska C. Detection of specific lgE as a screening tool for cow and swine breeders' occupational allergic dermatoses. Ann Agr Environ Med 2000; 7: 145-147.

27 Berger I, Schierl R, Ochmann U, Egger U, Scharrer E, Nowak D et al. Concentrations of dust, allergens and endotoxin in stables, living rooms and mattresses from cattle farmers in southern Bavaria. Ann Agr Environ Med 2005; 12: 101-107.

28 Kullman GJ, Thorne PS, Waldron PF, Marx JJ, Ault B, Lewis DM et al. Organic dust exposures from work in dairy barns. Am Ind Hyg Assoc J 1998; 59: 403-413.
29 van Hengel AJ. Food allergen detection methods and the challenge to protect food-allergic consumers. Anal Bioanal Chem 2007; 389.1: 111-118.

30 Hinze S, Bergmann KC, Løwenstein H, Hansen GN. Different threshold concentrations for sensitization by cattle hair allergen Bos $\mathrm{d} 2$ in atopic and nonatopic farmers. Pneumologie 1996; 50: 177.

31 Restani P, Beretta B, Fiocchi A, Ballabio C, Galli CL. Cross-reactivity between mammalian proteins. Ann Allergy Asthma Immunol 2002; 89: 11-15.

32 Purdy CW, Straus DC, Chirase N, Parker DB, Ayers JR, Hoover MD et al. Effects of aerosolized feedyard dust that contains natural endotoxins on adult sheep. $\mathrm{Am} \mathrm{J}$ Vet Res 2002; 63: 28-35.

33 Spaan S, Wouters IM, Oosting I, Doekes G, Heederik D. Exposure to inhalable dust and endotoxins in agricultural industries. J Environ Monitor 2006; 8: 63-72.

34 Madsen AM. Airborne endotoxin in different background environments and seasons. Ann Agr Environ Med 2006; 13: 81-86.

35 Purdy CW, Clark RN, Straus DC. Analysis of aerosolized particulates of feedyards located in the Southern High Plains of Texas. Aerosol Sci Tech 2007; 41: 497-509.

36 Purdy CW, Clark RN, Straus DC. Ambient and indoor particulate aerosols generated by dairies in the southern High Plains. J Dairy Sci 2009; 92: 6033-6045.

37 Mueller-Anneling L, Avol E, Peters JM, Thorne PS. Ambient endotoxin concentrations in PM10 from Southern California. Environ Health Persp 2004; 112: 583-588.

38 Mueller-Anneling L, O'Neill M, Thorne P. Biomonitoring for assessment of organic dust-induced lung inflammation. Eur Respir J 2006; 27: 1096-1101.

39 Waser M, Schierl R, von Mutius E, Maisch S, Carr D, Riedler J et al. Determinants of endotoxin levels in living environments of farmers' children and their peers from rural areas. Clin Exp Allergy 2004; 34: 389-397.

40 Schram D, Doekes G, Boeve M, Douwes J, Riedler J, Ublagger E et al. Bacterial and fungal components in house dust of farm children. Rudolf Steiner school children and reference children-the PARSIFAL Study. Allergy 2005; 60: 611-618.

41 Thorne PS, Kulhankova K, Yin M, Cohn R, Arbes SJ, Zeldin DC et al. Endotoxin exposure is a risk factor for asthma - The National Survey of Endotoxin in United States Housing. Am J Resp Crit Care 2005; 172: 1371-1377.

42 Park JH, Spiegelman DL, Gold DR, Burge HA, Milton DK. Predictors of airborne endotoxin in the home. Environ Health Persp 2001; 109: 859-864.

43 Thedell TD, Mull JC, Olenchock SA. A brief report of gram-negative bacterial endotoxin levels in airborne and settled dusts in animal confinement buildings. Am J Ind Med 1980; 1: 3-7.

44 Green CF, Gibbs SG, Tarwater PM, Mota LC, Scarpino PV. Bacterial plume emanating from the air surrounding swine confinement operations. J Occup Environ Hyg 2006; 3: 9-15.

45 Pew Charitable Trusts. Putting meat on the table: Industrial farm animal production in America. A Report of the Pew commission on industrial Farm Animal Production. A project of the Pew Charitable trusts and John Hopkins Bloomberg School of Public Health, Baltimore, MD, USA, 2008.

This work is licensed under a Creative Commons AttributionBy NG No NonCommercial-NoDerivs 3.0 Unported License. The images or other third party material in this article are included in the article's Creative Commons license, unless indicated otherwise in the credit line; if the material is not included under the Creative Commons license, users will need to obtain permission from the license holder to reproduce the material. To view a copy of this license, visit http://creativecommons.org/licenses/by-nc-nd/3.0/ 